\title{
Tautomerism in 1-hydroxy-2-naphthaldehyde Schiff bases: Calculation of tautomeric isomers using carbon-13 NMR
}

\author{
Salman R. Salman ${ }^{\text {a }}$ and Fadhil S. Kamounah ${ }^{\text {b,* }}$ \\ ${ }^{a}$ Department of Chemistry, College of Science, University of Qatar, P.O. Box 2713, Doha, Qatar \\ ${ }^{\mathrm{b}}$ Department of Chemistry, University of Copenhagen, Universitetsparken 5, DK-2100 Copenhagen, \\ Denmark
}

\begin{abstract}
Tautomeric equilibria in intramolecularly hydrogen bonded Schiff bases is studied on the basis of solution ${ }^{13} \mathrm{C}$ NMR chemical shifts. NMR spectroscopic data and comparison with two anils model compound, namely, salicylideneaniline (1A) and naphthalylidinequinoline (2A) were used to represent the enol (A) and the keto (H) forms. The ${ }^{13} \mathrm{C}$ NMR chemical shifts data of the novel series $4 \mathrm{~A}$ (compounds, 4-12) were used together with the values ${ }^{13} \mathrm{C}$ chemical shifts data of compounds $1 \mathrm{~A}$ and $2 \mathrm{~A}$ to calculate the $\%$ keto form. The calculated $\%$ keto form of $3 \mathrm{~A}$ was compared to that calculated for series $4 \mathrm{~A}$ compounds.

Keywords: Carbon-13 chemical shift, keto-enol equilibrium, UV-Vis spectroscopy, 1-hydroxy-2-naphthaldehyde Schiff bases, percentage of the keto form
\end{abstract}

\section{Introduction}

Tautomerism in Schiff bases derived from the condensation of salicylaldehyde and other aromatic aldehydes with anilines were the subject of a number of studies using different spectroscopic techniques.

It was found that some of these Schiff bases exist as enol form A [1-9], keto form $\mathrm{H}$ [10], or enol $\rightleftharpoons$ keto mixtures $\mathrm{A} \rightleftharpoons \mathrm{H}$ [11-18] (Scheme 1). UV-visible spectrum of Schiff bases which exists mainly as enol structure indicate the presence of a band at $<400 \mathrm{~nm}$, while compounds which exists either as keto or as mixture of enol-keto forms show a new band, especially in polar solvents at $>400 \mathrm{~nm}$. Different techniques were used to indicate the presence of the enol and keto equilibria $\mathrm{A} \rightleftharpoons \mathrm{H}$, among them is UV-visible, IR, ${ }^{1} \mathrm{H},{ }^{13} \mathrm{C}$ and ${ }^{15} \mathrm{~N}-\mathrm{NMR}$ spectroscopy.

It was suggested that Schiff bases derived from the condensation of salicylaldehyde and anilines $1 \mathrm{~A}$ are exists mainly in the enol-form in all solvents [5-7].

The $\%$ keto form in Schiff bases derived from the condensation of 2-hydroxy-1-naphthaldehyde with anilines $3 \mathrm{~A}$ increase in polar solvent and that substitution in the aniline ring effects significantly the enol-keto equilibrium [16].

Carbon-13 chemical shifts study of the 2-hydroxy Schiff bases series 3A [11,16] suggested that the percentage of the keto form in DMSO change from $38 \%$ when $\mathrm{R}=\mathrm{Ph}$ to $16 \%$ when $\mathrm{R}=$ naphthyl. The UV-visible data of this series was suggested that the band, which appears above $400 \mathrm{~nm}$ is due to the keto form [16].

\footnotetext{
${ }^{*}$ Corresponding author. Tel.: +45 353218 23; Fax: +45 392712 07; E-mail: f.kamounah@ symbion.ki.ku.dk.
} 
<smiles>Oc1ccccc1/C=N/c1ccccc1</smiles>

$1 \mathrm{~A}$<smiles>Oc1ccc2ccccc2c1/C=N/c1cccc2cccnc12</smiles>

$2 \mathrm{~A}$<smiles>Oc1ccc2ccccc2c1/C=N/c1ccccc1</smiles>

3A<smiles>[R]c1ccc(N=Cc2ccc3ccccc3c2O)cc1</smiles>

$4 \mathrm{~A}$<smiles>O=C1C=CC=C/C1=C/Nc1ccccc1</smiles>

$1 \mathrm{H}$

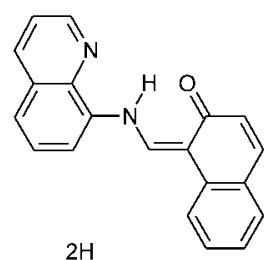

$2 \mathrm{H}$
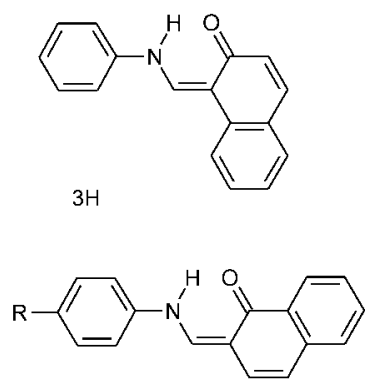

$4 \mathrm{H}$

$$
\begin{aligned}
& 4 \mathrm{R}=\mathrm{H} \\
& 5 \mathrm{R}=\mathrm{CH} 3 \\
& 6 \mathrm{R}=1 \\
& 7 \mathrm{R}=\mathrm{Br} \\
& 8 \mathrm{R}=\mathrm{OCH} 3 \\
& 9 \mathrm{R}=\mathrm{NMe} 2 \\
& 10 \mathrm{R}=\mathrm{NO} 2 \\
& 11 \mathrm{R}=\mathrm{Cl} \\
& 12 \mathrm{R}=\mathrm{CN}
\end{aligned}
$$

Scheme 1.

In this work a novel 1-hydroxy Schiff bases series 4A were prepared by the condensation of 1-hydroxy2-naphthaldehyde with anilines (compounds, 4-12).

The aim of this work, ${ }^{13} \mathrm{C}$ chemical shift of series $3 \mathrm{~A}$ was used to calculate the relative ratio between the enol and the keto form using the ${ }^{13} \mathrm{C}$ chemical shift of the two model compounds $1 \mathrm{~A}$ and $2 \mathrm{~A}$. The calculated \% keto form for series 4A is compared with that of Schiff bases derived from 2-hydroxy-1naphthaldehyde (series 3A).

\section{Experimental}

All solvents (Fluka) were of spectroscopic grade and used as such. Anil 1A was prepared previously [5] from the condensation of salicyaldehyde and aniline. Compound 2A was prepared from the condensation of 2-hydroxy-1-naphthaldehyde with 8-aminoquinoline [10]. Compound 3A was prepared from the condensation of 2-hydroxy-1-naphthaldehyde with aniline [11-17]. All Schiff bases were synthesized by a standard procedure [5-18] and were recrystallized (twice) from ethanol until show a sharp 
melting points, also a satisfactory microanalysis was obtained: $\mathrm{C} \pm 0.4 \%, \mathrm{H} \pm 0.2 \%$ and $\mathrm{N} \pm 0.3 \%$. The structure elucidation for all compounds of series $3 \mathrm{~A}$ and $4 \mathrm{~A}$ were confirmed by a satisfactory ${ }^{1} \mathrm{H}-\mathrm{NMR}$, ${ }^{13} \mathrm{C}$-NMR and mass spectra. UV-visible spectra were recorded using Perkin Elmer EZ 210. The ${ }^{13} \mathrm{C}$ spectra of solutions of series $3 \mathrm{~A}$ in $\mathrm{CDCl}_{3}$ were measured on Bruker $400 \mathrm{MHz}$ spectrometer operating at $100.573 \mathrm{MHz}$, and at $303 \mathrm{~K}$. Typical spectral parameters were as follows: spectral width, $25000 \mathrm{~Hz}$; acquisition time $1.99 \mathrm{~s} ; 1000$ transient; delay time $1.0 \mathrm{~s}$; pulse width $10 \mu \mathrm{sec}$; line broading $1 \mathrm{~Hz}$. The UV-visible were run for a solution of optimal concentration of $5 \times 10^{-5} \mathrm{M}$ using a quartz cell of $1.0 \mathrm{~cm}$ path length.

\section{Results and discussion}

Using the absorbency of the keto form $A_{\text {keto }}$ and the enol form $A_{\text {enol }}$ obtained from the UV-visible spectrum of each compound it was possible to calculate the approximate $\%$ of each form. Table 1 shows the approximate percentage of the keto forms in $3 \mathrm{~A}$ and $4 \mathrm{~A}$ based on the approximate calculations that the $A_{\text {enol }}+A_{\text {keto }}=100 \%$. Table 1 show that in series $4 \mathrm{~A}$ the keto form $4 \mathrm{H}$ is higher than $3 \mathrm{H}$ for $3 \mathrm{~A}$ series in all solvents. The keto form in $4 \mathrm{H}$ is the dominant structure in all solvents except cyclohexane. In series $3 \mathrm{~A}$ and even in polar solvents the enol form is the dominant structure.

From previous studies it was found that compound $1 \mathrm{~A}$ exists mainly in the enol form while compound $2 \mathrm{~A}$ exists in the keto form $2 \mathrm{H}$, therefore ${ }^{13} \mathrm{C}$ chemical shift of the carbon atom attached to the hydroxyl group in series 1A (163.7 ppm) and 2A (181.8 ppm) will be used as model compounds from which we can calculate the $\%$ keto form in series $4 \mathrm{~A}$ (compounds 4-12). The appearance of one set of ${ }^{13} \mathrm{C}$ signals for each tautomer for the studied compounds support the fact of a fast proton transfer between the two tautomeric forms and allows us to use the equation below

$$
\delta_{\mathrm{ob}}=\delta_{\mathrm{K}} P_{\mathrm{K}}+\delta_{\mathrm{E}} P_{\mathrm{E}}
$$

The ratio of the keto forms for series $4 \mathrm{~A}$ can be calculated from the ${ }^{13} \mathrm{C}$ chemical shifts of the model compounds $1 \mathrm{~A}$ and $2 \mathrm{~A}$, where $\delta_{\mathrm{K}}$ represent the ${ }^{13} \mathrm{C}$ chemical shift values for the model compound $2 \mathrm{~A}$ and $\delta_{\mathrm{E}}$ for the model compound $1 \mathrm{~A}$.

Equation (1) can be used to calculate the keto and the enol percentage in compounds of series $4 \mathrm{~A}$ (Table 2) using the ${ }^{13} \mathrm{C}$ chemical shifts of the carbons under study when it is in the enol (series 4A), in the keto form $(4 \mathrm{H})$, together with the observed carbon chemical shift of compounds 4-12 which represent a mixture of both of them and taking into account that

$$
P_{\mathrm{K}}+P_{\mathrm{E}}=1
$$

The keto form can be calculated by using ${ }^{13} \mathrm{C}$ chemical shifts of $\mathrm{C}-\mathrm{H}, \mathrm{C}=\mathrm{O}$, and $\mathrm{C}-\mathrm{N}_{\mathrm{Ar}}$ (Table 3). In this work the most reasonable $\%$ keto values was obtained when using the ${ }^{13} \mathrm{C}$ chemical shift of the carbonyl group.

$$
\begin{aligned}
K_{\mathrm{eq}} & =\frac{\delta_{\mathrm{ob}}-\delta_{\mathrm{E}}}{\delta_{\mathrm{K}}-\delta_{\mathrm{ob}}}, \\
\Delta G & =-R T \ln K_{\mathrm{eq}} .
\end{aligned}
$$


Table 1

Approximate keto and enol percentage in different solvents

\begin{tabular}{lcc}
\hline Solvent & 4A, \%keto & 3A, \%keto \\
\hline Cyclohexane & 35.1 & 14.6 \\
Ethanol & 69.0 & 38.8 \\
DMSO & 70.0 & 51.1 \\
$\mathrm{CHCl}_{3}$ & 70.9 & 50.6 \\
\hline
\end{tabular}

Table 2

${ }^{13} \mathrm{C}$ chemical shift for compounds 4-12 in $\mathrm{CDCl}_{3}$

\begin{tabular}{rccccccccc}
\hline & $\mathrm{H}$ & $\mathrm{CH}_{3}$ & $\mathrm{OCH}_{3}$ & $\mathrm{Cl}$ & $\mathrm{Br}$ & $\mathrm{I}$ & $\mathrm{CN}$ & $\mathrm{NO}_{2}$ & $\mathrm{~N}\left(\mathrm{CH}_{3}\right)_{2}$ \\
\hline 1 & 172.33 & 172.41 & 169.98 & 169.09 & 169.30 & 169.76 & 169.77 & 170.17 & 170.88 \\
2 & 110.77 & 110.66 & 110.87 & 111.18 & 111.21 & 111.16 & 109.12 & 111.70 & 110.73 \\
3 & 124.86 & 124.85 & 124.56 & 124.56 & 124.62 & 124.64 & 124.75 & 124.84 & 124.62 \\
4 & 116.93 & 116.68 & 116.80 & 117.64 & 127.32 & 117.64 & 118.43 & 118.72 & 116.20 \\
5 & 127.48 & 127.49 & 127.35 & 127.26 & 117.68 & 127.36 & 127.43 & 127.49 & 127.42 \\
6 & 130.11 & 130.17 & 129.61 & 129.91 & 129.98 & 130.03 & 130.47 & 130.65 & 129.45 \\
7 & 127.29 & 127.28 & 127.27 & 127.22 & 127.26 & 127.23 & 127.11 & 127.10 & 127.23 \\
8 & 125.38 & 125.31 & 125.25 & 125.53 & 125.57 & 125.55 & 125.83 & 125.48 & 125.08 \\
9 & 128.22 & 128.34 & 127.75 & 127.35 & 127.37 & 127.40 & 127.43 & 130.49 & 128.19 \\
10 & 136.94 & 136.92 & 136.70 & 136.66 & 136.70 & 136.73 & 136.88 & 136.97 & 136.59 \\
11 & 155.84 & 155.41 & 155.92 & 157.65 & 157.53 & 157.18 & 158.06 & 158.05 & 153.89 \\
13 & 142.84 & 140.19 & 136.60 & 142.93 & 143.35 & 143.83 & 148.23 & 150.00 & 129.45 \\
14 & 119.22 & 119.07 & 120.72 & 120.91 & 121.26 & 121.47 & 120.16 & 119.85 & 120.44 \\
15 & 129.59 & 130.17 & 114.77 & 129.62 & 132.60 & 138.54 & 133.63 & 125.58 & 113.05 \\
16 & 126.11 & 136.14 & 158.19 & 131.68 & 119.46 & 90.20 & 111.49 & 145.20 & 148.00 \\
$\mathrm{CH}_{3}$ & - & 20.88 & 55.42 & - & - & - & - & - & 40.59 \\
\hline
\end{tabular}

Table 3

Calculated \% keto of compounds 4-12 in $\mathrm{CDCl}_{3}$ using ${ }^{13} \mathrm{C}$ chemical shift data

\begin{tabular}{lllcr}
\hline Compound & $\begin{array}{c}\text { \%keto } \\
\delta_{\mathrm{C}=\mathrm{O}}\end{array}$ & $\begin{array}{c}\text { \%keto } \\
\delta_{\mathrm{CH}}\end{array}$ & $\begin{array}{c}K_{\text {eq }} \\
\text { from C=O }\end{array}$ & $\begin{array}{c}\Delta G \\
(\mathrm{~kJ} / \mathrm{mol})\end{array}$ \\
\hline $\mathrm{H}$ & $48.8(38.0)$ & $44.2(50.0)$ & 0.95 & +0.118 \\
$\mathrm{CH}_{3}$ & $49.2(39.0)$ & $48.4(53.0)$ & 0.97 & +0.083 \\
$\mathrm{OCH}_{3}$ & $36.1(31.0)$ & $20.9(57.0)$ & 0.36 & -2.532 \\
$\mathrm{Cl}$ & 31.3 & 26.2 & 0.45 & -1.957 \\
$\mathrm{Br}$ & $32.4(30.0)$ & $27.4(38.0)$ & 0.48 & -1.818 \\
$\mathrm{I}$ & $34.9(31.0)$ & $30.9(42.0)$ & 0.54 & -1.540 \\
$\mathrm{CN}$ & 35.0 & 22.2 & 0.54 & -1.537 \\
$\mathrm{NO}_{3}$ & 37.5 & 22.3 & 0.60 & -1.270 \\
$\mathrm{~N}_{(}\left(\mathrm{CH}_{3}\right)_{2}$ & $41.0(24.0)$ & $63.5(82.0)$ & 0.41 & -2.216 \\
\hline
\end{tabular}

() $\%$ keto for $3 \mathrm{~A}$ series.

Taking into account that $\delta_{\mathrm{E}}=163.7 \mathrm{ppm}$ and $\delta_{\mathrm{K}}=181.8 \mathrm{ppm}$, the calculated values for the studied compounds are given in Table 3.

The ${ }^{13} \mathrm{C}$ chemical shift of the carbon atom attached to the hydroxyl group in the model compound $3 \mathrm{~A}$ is equal $181.8 \mathrm{ppm}$, very similar to the carbonyl carbon in typical aromatic keto compounds, suggesting 
that this carbon exists as a keto carbon. This suggests a complete transfer of the proton from the oxygen atom to the nitrogen atom. Therefore as the ${ }^{13} \mathrm{C}$ chemical shift of the carbon atom at position 1 in this series approach the model value of $181.8 \mathrm{ppm}$ the keto percentage increase. It was reported [16] that increasing conjugation decreases the percentage keto form. This is also observed in this series therefore the keto percentage decrease in going from compound 1 to compound 8 and 9. Close examination of the results indicates that conjugation is not the sole factor determining the percentage of the keto form.

The data in Table 3 suggested that for compounds 4 and 5 the keto and the enol forms are nearly at equilibrium in $\mathrm{CDCl}_{3}$ solution, while the $K_{\mathrm{eq}}$ and $\Delta G$ values for other compounds suggest that the equilibrium be shifted to the enol form.

The chemical shifts data reported in Table 2 for compounds of series 4A (4-12) are all indicative that appreciable amounts of both tautomers exist at equilibrium in this case, based on the assignment of ${ }^{13} \mathrm{C}$ NMR chemical shifts data of previous reports $[10,11,16]$ and using additivity rules with reported substitution effects in naphthalene derivatives $[19,20]$. In the compounds presently studied, were R substituents affect the chemical shifts of the aromatic carbons C-13, C-14 and C-16, the carbon of choice to study changes in equilibrium compositions is the $\mathrm{C}-\mathrm{O}$, carbon $\mathrm{C}-1$. A qualitative information in this regards can also be drawn from carbons C-2, C-4, and C-13. According to this assignment, the carbon C-1 for series 4A appears deshielded at about $174.4 \mathrm{ppm}$, while that of C-2 shielded at about $110.0 \mathrm{ppm}$. The chemical shift observed for C-1 throughout the 4A series is rather high for an aromatic quaternary carbon, but may be explained as the result of a significant contribution of the keto form $4 \mathrm{H}$. In general, no appreciable changes in the equilibrium chemical shifts are observed upon changing the substituent $\mathrm{R}$, with the exception of $\mathrm{C}-11$, were a chemical shifts of $155.41,158.05$ and $153.89 \mathrm{ppm}$ observed for $\mathrm{CH}_{3}, \mathrm{NO}_{2}$ and $\mathrm{NMe}_{2}$ substituents, respectively. As expected, C-1, C-11 and C-13 chemical shifts are considerably effected by the nature of the substituents $\mathrm{R}$ (Table 2).

On the other hand, calculated \% keto values in different solvents reported in Table 1 for Schiff bases of 1-hydroxy-2-naphthaldehyde (4A series) and 2-hydroxy-1-naphthaldehyde (3A series) indicates that the keto tautomer is dominating for series $4 \mathrm{~A}$ relative to series $3 \mathrm{~A}$ and this possibly can be explained in term of the peri-proton (H-8) which may cause stabilization of the keto group via pseudo H-bond [21].

\section{References}

[1] G.H. Brown and W.G. Shaw, Rev. Pure Appl. Chem. 11 (1961), 1.

[2] M.D. Cohen and S. Flavian, J. Chem. Soc. B (1967), 321.

[3] J.W. Ledbetter, Jr., J. Phys. Chem. 72 (1968), 4111.

[4] G.O. Dudek and E.P. Dudek, J. Am. Chem. Soc. 88 (1966), 2407.

[5] S.R. Salman, S.H. Shawkat and G.M. Al-Obaidi, Can. J. Spectrosc. 35 (1990), 25.

[6] F.S. Kamounah, S.H. Shawkat and S.R. Salman, Spectrosc. Lett. 25(4) (1992), 513.

[7] S.R. Salman, S.H. Shawkat and F.S. Kamounah, Can. J. Appl. Spectrosc. 37 (1992), 46.

[8] S.R. Salman, R.H. Shawkat and G.M. Al-Obaidi, Spectrosc. Lett. 22(10) (1989), 1265.

[9] L. Antonov, W.M.F. Fabian, D. Nedeltcheva and F.S. Kamounah, J. Chem. Soc., Perkin Trans. 2(6) (2000), 1173.

[10] S.R. Salman, R.D. Farrant and J.C. Lindon, Spectrosc. Lett. 24 (1991), 1071.

[11] S.R. Salman, J.C. Lindon, R.D. Farrant and T.A. Carpenter, Mag. Res. Chem. 31 (1993), 991.

[12] S.R. Salman, A.G. Petros, B.C. Sweatman and J.C. Lindon, Can. J. Appl. Spectorsc. 39 (1994), 1.

[13] S.H. Alarcon and A.C. Olivieri, Tetrahedron 51 (1995), 4619.

[14] F.S. Kamounah and S.R. Salman, Spectrosc. Lett. 29(4) (1995), 659.

[15] K.A. Abbas, S.R. Salman, S.M. Kana'n and Z.A. Fatafteh, Can. J. Appl. Chem. Spectrosc. 41(5) (1996), 119.

[16] S.R. Salman and Nai'l A.I. Saleh, Can. J. Anal. Sci. Spectrosc. 42(1) (1997), 9.

[17] H. Joshi, F.S. Kamounah, G. van der Zwan, C. Gooijier and L. Antonov, J. Chem. Soc., Perkin Trans. 2(12) (2001), 2303.

[18] S.R. Salman and Nai'l A.I. Saleh, Spectrosc. Lett. 31(6) (1998), 1179. 
[19] E. Pretsch, T. Clare and W. Simon, Spectral Data for Structure Determination of Organic Organic Compounds, Springer, Berlin, 1983

[20] D.P. Wells, P.R. Arnold and D. Doddrell, J. Chem. Soc., Perkin Trans. 2 (1974), 1745.

[21] S. Perumal, G. Vasuki and D.A. Wilson, Magn. Reson. Chem. 28 (1990), 257. 


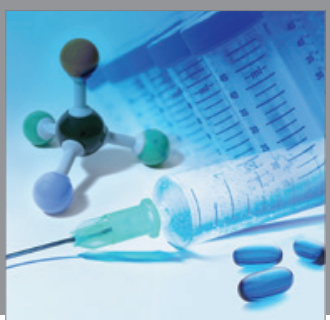

International Journal of

Medicinal Chemistry

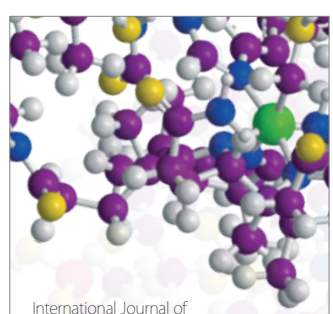

Carbohydrate Chemistry

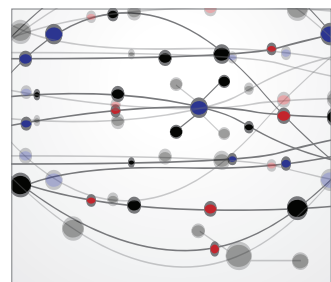

The Scientific World Journal
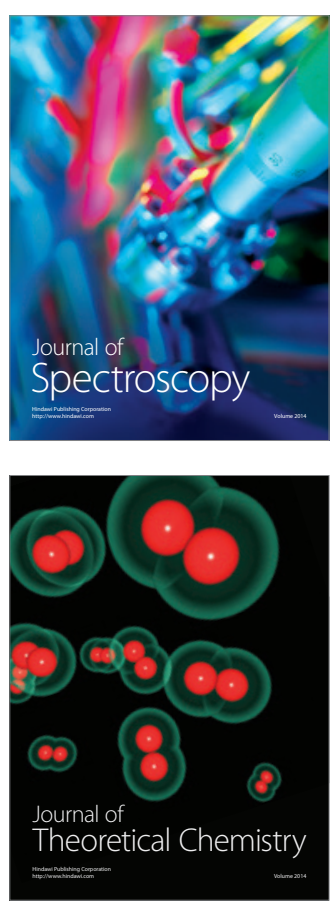
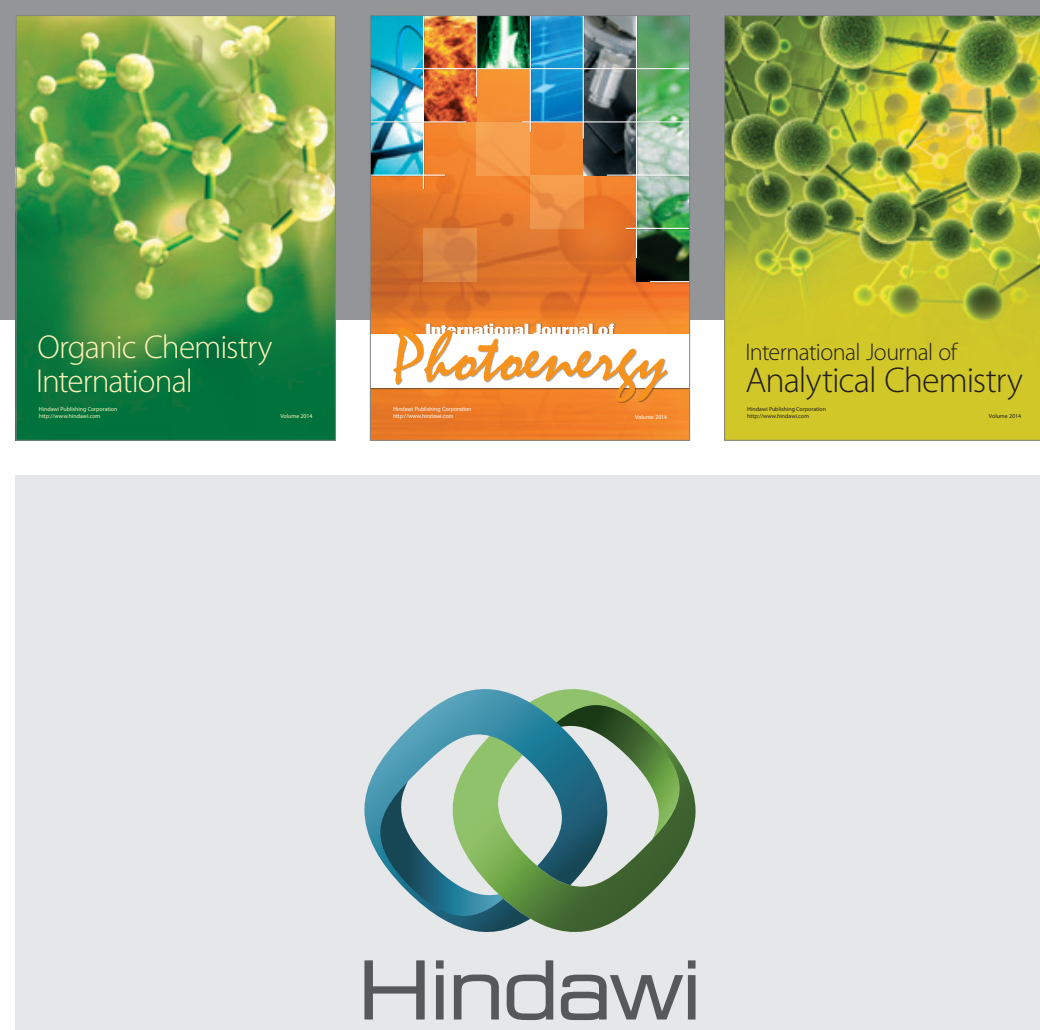

Submit your manuscripts at

http://www.hindawi.com
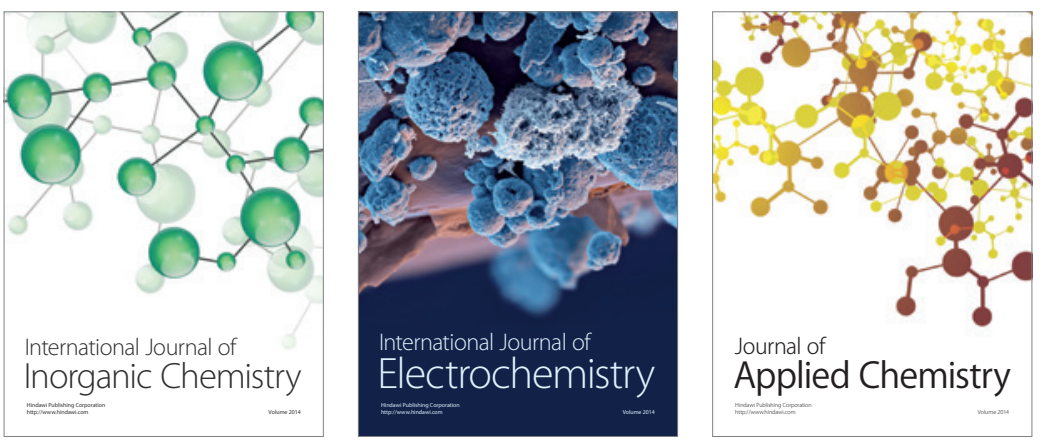

Journal of

Applied Chemistry
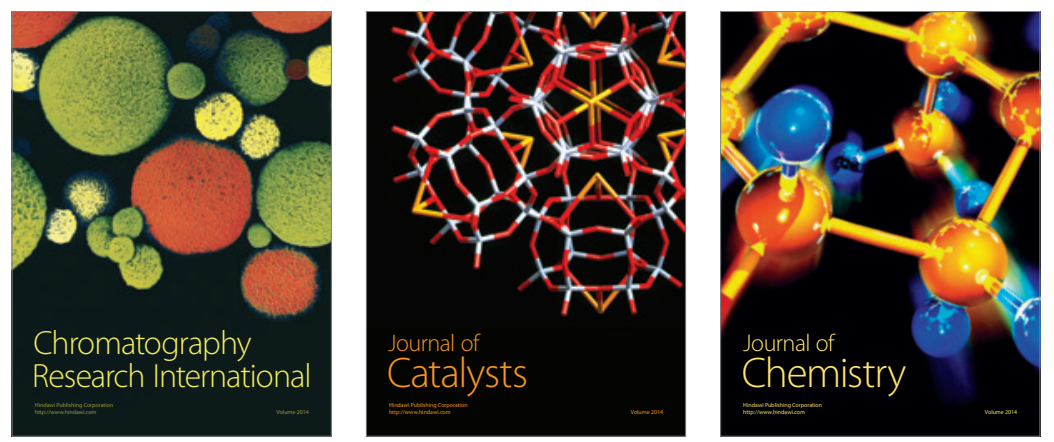
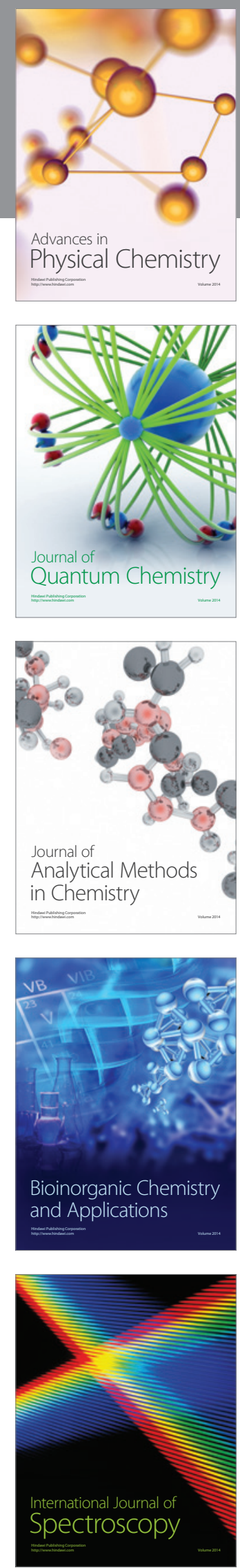